\title{
CONSCIÊNCIA HISTÓRICA E HERMENÊUTICA: CONSIDERAÇÕES DE GADAMER ACERCA DA TEORIA DA HISTÓRIA DE DILTHEY ${ }^{1}$
}

Evandro Oliveira de Brito ${ }^{2}$

- RESUMO: O propósito deste artigo é explicitar o modo como Gadamer reformula a hermenêutica diltheiana (desenvolvida sobre o conceito moderno de vida utilizado como fundamento da noção de auto-consciência histórica), ao formular um novo modo de compreender a razão e a existência humanas, tomando como ponto de partida a experiência concreta da finitude da vida humana.

- PALAVRAS-CHAVE: hermenêutica, consciência histórica, verdade, finitude.

\section{Introdução}

As considerações preliminares apresentadas por Gadamer na segunda parte de seu livro Verdade e método mostram claramente a discrepância nos propósitos de Gadamer e Dilthey para com a hermenêutica. ${ }^{3}$ Dilthey segue os passos de Schleiermacher ao radicalizar a tentativa de liberar a compreensão histórica de todos os pressupostos dogmáticos e, como conseqüência, fundamenta a autoconsciência histórica na vida. Gadamer, por sua vez, assume a tarefa de refazer o caminho aberto por Dilthey com o intuito de explicitar um novo modo de compreender a razão e a existência humanas, tomando como ponto de partida a experiência concreta dos homens e sua finitude. Neste sentido, a segunda parte da obra Verdade e método (A extensão da compreensão da verdade à compreensão nas ciências do espírito) apresenta o fundamento da possibilidade da "liberação da verdade a partir

1 Artigo recebido em 02/2205; aprovado para publicação em 06/2005

2 Professor da UDESC e doutorando em filosofia pela PUC-SP; evandrobritobr@yahoo.com.br

3 Gadamer, Verdade e método, p. 273. 
da experiência da arte", proposta na primeira parte da obra. Em outras palavras, o propósito de Gadamer é, por um lado, mostrar que há uma tradição histórica de liberação da verdade que não se restringe ao modelo estabelecido pelas ciências da natureza, e por outro lado, afirmar que a hermenêutica tem como meta levar a cabo a realização desta tarefa, segundo o modelo que ele mesmo sugere: o "palmilhar o desenvolvimento do método hermenêutico na idade moderna, que desemboca na consciência histórica". 4

A discrepância entre Gadamer e Dilthey, portanto, pode ser entendida à luz das considerações de Gadamer acerca dos limites e das inconsistências na própria teoria da história de Dilthey. Mas, de modo mais preciso, a análise de Gadamer expõe os pontos fracos da proposta de Dilthey justamente no modo como este se apropria da hermenêutica para estabelecer a correspondência entre os conceitos de vida e consciência histórica.

Não temos como objetivo explicitar, no presente texto, o modo como Gadamer reformula e estabelece efetivamente a hermenêutica. Deter-nosemos apenas em alguns pontos fundamentais da análise gadameriana acerca da consciência histórica. Assim, apresentaremos o modo como Gadamer explicita a história do desenvolvimento desse conceito que culmina em Dilthey, para então apontar os seus limites e as suas inconsistências.

\section{O propósito de Gadamer}

Gadamer afirma compartilhar com Dilthey a tese de que a consciência histórica está na base de qualquer liberação da verdade para além do método estabelecido pelas ciências da natureza. ${ }^{5}$ No entanto, para Gadamer é a hermenêutica que deve dar conta da possibilidade de compreensão das ciências do espírito e, para isto, a tarefa da filosofia deve fundamentála a partir da própria finitude humana em seu contexto existencial de comunicação. Dilthey, por sua vez, retrocede ao modelo kantiano para tentar explicitar as condições de possibilidades de compreensão das ciências do espírito. O que ele (Dilthey) busca com este retorno é, por um lado, conferir à hermenêutica um estatuto de maior maturidade e consistência (relativamente à utilização que Ranke e Droysen dela fizeram). Mas, por outro lado,

4 Idem.

5 "A aparição de uma tomada de consciência histórica é, possivelmente, a mais importante revolução por que passamos desde o surgimento da época moderna. O seu alcance espiritual ultrapassa, provavelmente, aquele que reconhecemos às realizações da natureza, as quais transformaram, de uma forma bem visível, a face do nosso planeta. A consciência histórica que caracteriza o homem atual é um privilégio, talvez mesmo um fardo tal como nenhum outro que tenha sido imposto a algumas gerações anteriores" (Gadamer, O Problema da Consciência Histórica, p. 17). 
Dilthey recusa assumir deliberadamente a tese da filosofia especulativa elaborada por Hegel. Neste sentido, o trabalho de Dilthey deve ser entendido como uma tentativa de solução do problema da mediação histórica. Ou seja, o que coloca Dilthey a meio caminho entre Schleiermacher e Hegel é a epistemologia que ele elabora se valendo da hermenêutica para dar conta dos conceitos de reconstrução e integração. Portanto, quando Gadamer aponta para o problema de que a "compreensão co-implica sempre uma mediação histórica" ${ }^{6}$ e, com isto, pergunta "como se irá determinar a tarefa da hermenêutica", ele (Gadamer) [1] encontra um ponto comum entre Schleiermacher e Hegel ao mostrar que ambas as teses podem ser designadas pelos conceitos de reconstrução e integração. [2] Esta tarefa da hermenêutica (reconstrução e integração) é determinada por cada um de maneira diferente. [3] Dilthey, ainda que trate do mesmo problema, o faz de um modo original também a meio caminho entre Schleiermacher e Hegel, pois Gadamer afirma que

Schleiermacher e Hegel poderia apresentar as duas possibilidades extremas de resposta a esta pergunta. As suas respostas poderiam ser designadas com os conceitos de reconstrução e integração. Tanto para Schleiermacher como para Hegel, no começo se encontra a consciência de uma perda e [de uma] alienação frente à tradição, que é a que move a reflexão hermenêutica. Entretanto, eles determinam a tarefa da hermenêutica cada um de maneira diferente. ${ }^{7}$

É muito esclarecedor percebermos o contexto argumentativo em que Gadamer propõe a comparação citada no parágrafo acima. Justamente naquilo que seria a conclusão da sua análise sobre a liberação da questão da verdade (também na arte e não apenas nas ciências da natureza), se impõe a mediação histórica e, portanto, hermenêutica como a gênese da consciência histórica. ${ }^{8}$ Neste contexto, ainda, a hermenêutica elaborada por Dilthey é citada como um trabalho a ser aprimorado por meio da "subtração dos preconceitos da história do espírito fundados por ele". ${ }^{9}$ Mas, qual é exatamente a posição de Dilthey se o próprio Gadamer afirma que ele, como hermeneuta, compartilha preconceitos da história do espírito?

No intuito de explicitar a análise de Gadamer de um modo claro, apresentaremos primeiramente o modo como Schleiermacher e Hegel elaboram aquilo que Gadamer define como reconstrução e reintegração diante da perda e da alienação diante da tradição. O certo é que estes argumentos

6 Gadamer, Verdade e método, p. 265.

7 Idem.

8 Cf. Gadamer, Verdade e método, p. 265

9 Gadamer, Verdade e método, p. 264. 
tratam diretamente da liberação da verdade pela experiência da arte. Todavia, a análise esclarece a natureza da consciência histórica pelo fato de, por um lado, a própria liberação da verdade pela arte implicar mediação histórica, e, por outro lado, ficar caracterizado que a divergência teórica se dá em função da concepção de tempo admitida por cada autor.

\section{Schleiermacher}

"O que importa é compreender um autor melhor do que ele próprio se teria compreendido." Esta é a tese célebre de Schleiermacher que, no entender de Gadamer, evidencia que o ato de compreensão é a realização reconstrutiva de uma produção. Em outras palavras, a vantagem própria daquele que compreende, relativamente ao autor, está no fato de que o primeiro pode se tornar consciente de algo que no autor original tenha ficado inconsciente. Quanto à produção e à reprodução, portanto, a hermenêutica geral de Schleiermacher pressupõe a estética do gênio. Ademais, diz Gadamer: "o modo de criar do artista genial é o caso-modelo, a que se reporta a teoria da produção inconsciente e da consciência necessária na reprodução". ${ }^{10}$

A proposta de Schleiermacher afirma a possibilidade de reconstruir na compreensão a determinação original de uma obra. Assim, poderíamos reconstruir o sentido de uma obra de arte ou literária transmitida do passado e que, por isso, nos chega desenraizada de seu mundo original. Para caracterizar a pertinência de uma obra à sua época, Schleiermacher parte do pressuposto de que o natural e o originário deixam de existir

\footnotetext{
(...) a partir do momento em que as obras de arte entram em circulação. Ou seja, cada uma (obra) tem uma parte de sua compreensibilidade a partir de sua compreensão original (...). Por isso, a obra de arte perde algo de sua significância quando é arrancada de seu contexto originário e este não se conserva historicamente (...). Assim, uma obra de arte está enraizada, na realidade, também no seu solo e chão, no seu contexto. Ela já perde o seu significado ao ser retirada desse contexto, e ao entrar em circulação é como algo que foi salvo do fogo e agora traz as marcas de queimado. ${ }^{11}$
}

Seguindo essas considerações de Schleiermacher, apontadas por Gadamer, podemos afirmar que o verdadeiro significado de uma obra de arte resulta da reconstrução do originário. Do mesmo modo, devemos reconhecer que a obra de arte não é um objeto atemporal da vivência estética, pois

10 Idem, p. 299

11 Schleiermacher, Ästhetik, ed. R. Odebrecht, pp. 84ss., in: Gadamer, Verdade e método, p. 265. 
ela pertence a um mundo específico: o único mundo capaz de determinar plenamente o seu significado.

Com destas considerações de Gadamer, ficam explicitados os aspectos tácitos da hermenêutica de Schleiermacher. Em outras palavras, a reconstrução do mundo a que pertence uma obra de arte, a reconstrução do estado originário que existiu na intenção do artista criador, a execução no estilo original, bem como todos os meios de reconstrução histórica, têm o direito de reivindicar o fato de que eles tornam compreensível o verdadeiro significado da obra de arte e, ao mesmo tempo, protegem contra mal-entendidos e falsas atualizações. ${ }^{12} \mathrm{Na}$ verdade, cabe ao saber histórico (e a ele somente por meio dos procedimentos hermenêuticos gramatical e psicológico ${ }^{13}$ ) recuperar aquilo que foi perdido, bem como reconstruir a tradição, uma vez que nos devolve o ocasional e o originário. Assim, conclui Gadamer:

o empenho hermenêutico (segundo Schleiermacher) se orienta para a recuperação do ponto de conexão com o espírito do artista, que é o que deve fazer inteiramente compreensível o significado de uma obra de arte; procede como, fora isso, o faz ante textos, procurando re-produzir o que foi a produção original do autor. ${ }^{14}$

Antes de passarmos para a exposição da proposta hegeliana de reconstrução e integração, cabe ressaltar que Gadamer aponta explicitamente um limite na proposta de Schleiermacher. Para Gadamer, ainda que a compreensão exija uma operação de reconstrução das condições de origem, esta reconstrução é apenas uma existência secundária na cultura. Portanto, o que alcança Schleiermacher por este caminho é algo diferente daquilo que ele busca ao almejar o sentido originário da produção da obra. É justa-

12 Cf. Gadamer, Verdade e método, p. 265ss.

13 Sobre os dois modos de procedimento da hermenêutica (gramatical e psicológico), cabe apresentar as considerações sobre o trabalho de José Aguirre acerca dos mesmos. Diz ele: "Schleiermacher concebe a hermenêutica como sendo suportada por dois momentos fundamentais que se interpenetram. Um deles assume um cunho essencialmente gramatical, uma vez que representa o discurso em sua faceta mais comum, mais ordinária, que se consubstancia em tudo aquilo que acontece, independentemente da intervenção da singularidade individual e que se revela no uso que fazemos das palavras, das línguas e dos conceitos. O outro corresponde ao momento psicológico, que se traduz não somente na compreensão literal das palavras e do seu sentido objetivo, mas tem sobretudo presente a individualidade do locutor ou do autor, sua genialidade. Esta dimensão da compreensão representa a sua faceta positiva, aquela que torna possível captar a referida individualidade de uma forma direta ou intuitiva, assumindo como objetivo a reconstrução mental (da "intenção") do autor do texto. Embora estas duas dimensões devam ser entendidas na sua interação recíproca, pressupondo neste sentido um acordo entre pensamento e linguagem, é a partir de 1819 que a vertente técnica da hermenêutica adquire mais importância e se desenvolve no sentido de uma interpretação psicológica" (cf. Aguirre, Raison critique et raison herméneutique, p. 83

14 Gadamer, Verdade e método, p. 266. 
mente este limite que a filosofia de Hegel havia superado, embora tivesse de afirmar uma especulação metafísica.

\section{Hegel}

$\mathrm{Na}$ visão de Gadamer, Hegel oferece uma possibilidade diferente de compensar entre si o ganho e a perda da empresa hermenêutica. Pois, o que faz Hegel é apontar para além da dimensão global em que se havia apresentado o problema da compreensão em Schleiermacher. Para Hegel, o fundamento de toda reconstrução e integração (como conceitua Gadamer a tarefa da hermenêutica) é a filosofia como a forma mais alta do espírito absoluto. No saber absoluto da filosofia, uma vez que se trata aqui do autoconhecimento do espírito em seu processo de realização na (e pela) história, leva-se a cabo a própria autoconsciência do espírito, a única capaz de abranger a verdade da arte de um modo superior.

A superioridade da filosofia hegeliana frente à hermenêutica de Schleiermaher é apresentada por Gadamer em metáfora muito elucidativa: a metáfora dos frutos colhidos. Assim, diz Hegel:

As obras das musas são agora o que são para nós - belos frutos arrancados da árvore; um destino amável no-lo ofereceu, como uma jovem presenteia aqueles frutos; não existe a vida real na existência, não existe a árvore que os produziu, não há a árvore nem os elementos que perfizeram sua existência nem o clima que perfez sua determinação, nem a mudança das estações que dominavam o processo de seu devir. Assim, como as obras daquela arte, o destino não nos dá o mundo, nem a primavera ou o verão da vida moral em que floresceram e maduraram, mas apenas a lembrança velada daquela realidade. ${ }^{15}$

Assim como os frutos arrancados perdem a sua ligação essencial com o seu habitat, a obra de arte também foi arrancada de seu contexto e não mais se relaciona com seu contexto de produção, ou seu mundo cultural, no sentido que pretendia Schleiermacher. Mas então toda tentativa de compreensão é vã e não passa de uma atividade infrutífera guiada por uma nostalgia cega? A continuação da metáfora dos frutos colhidos afirma que todo este trabalho não passa de um labor externo:

Talvez retire uma gota de chuva ou um pozinho desses frutos, e que em lugar dos elementos ulteriores da realidade do ético, que os rodeava, que os produziu e lhes deu alma, erige o aparato prolixo dos elementos mortos de sua existência exter-

15 Hegel. Phänomenologie des Geistes, ed Hoffmeister, p. 524, in: Gadamer, Verdade e método, p. 267. 
na, da linguagem, do histórico, etc., não para adentrá-los, experimentando-lhes a vida, mas somente para imaginá-los. ${ }^{16}$

Gadamer elucida que Hegel trata aqui diretamente daquilo que Schleiermacher exigia para a conservação histórica. No entanto, a filosofia hegeliana não respalda qualquer investigação ocasional que pretenda constituir o significado das obras de arte. Ou seja, Hegel entende que o retorno ao contexto histórico não estabelece nenhuma relação vital, pois o que se obtém é apenas uma relação imaginativa. Desta maneira, conforme Hegel, Schleiermacher estaria propondo investigar um suposto comportamento histórico que não passaria de um labor externo.

O que Hegel quer expressar, diz Gadamer, é uma verdadeira categoria ao afirmar que a essência do espírito histórico não consiste na restituição do passado, mas na mediação do pensamento com a vida atual. Isto se confirma com o desfecho da metáfora utilizada acima.

Mas tal qual a jovem que nos oferece a fruta colhida, é mais que uma natureza, na medida em que a jovem, no brilho do olhar autoconsciente do gesto que oferece, reúne tudo isto de maneira superior, assim também o espírito do destino, que nos oferece aquela obra de arte, é mais que a vida ética e a realidade daquele povo, pois é a recordação (Er-Innerung) do espírito que nele ainda está exteriorizado - é o espírito do destino trágico que reúne todos aqueles deuses e atributos individuais da substância no panteão uno, no espírito autoconsciente de si mesmo como espírito. ${ }^{17}$

De fato, como afirma Gadamer, a pretensão de Hegel ultrapassa fundamentalmente a idéia hermenêutica de Schleiermacher na proposta de concepção da verdade da arte. Mas trata-se ainda de um modo de pensar a história a partir de um padrão situado além dela própria. Certamente há aqui uma reconciliação estética modular entre a Antigüidade Clássica e a autoconsciência do presente. É esta reconciliação que caracteriza a religião da arte dos gregos como uma figura já superada do espírito e, ao mesmo tempo, encontra a perfeição da história no presente, pois é no presente que se dá a autoconsciência filosófica da liberdade. ${ }^{18}$

Se a hermenêutica de Schleiermacher pressupunha o acesso a um mundo de significados fora da própria história, a teoria hegeliana não é menos exigente. Também aqui se impõe a pressuposição de um paradigma apriorístico fora da própria história. É justamente este problema que Gadamer aponta como sendo uma tarefa não solucionada no século XIX; mesmo

\footnotetext{
16 Idem.

17 Idem.

18 Gadamer, Verdade e método, pp. 311ss.
} 
aqueles que, como Dilthey, polemizaram com o conceito idealista do espírito, ainda mantiveram referência a ele.

Mas, em que consiste exatamente a originalidade e os limites da teoria de Dilthey?

\section{Dilthey}

Se queremos situar a posição de Dilthey entre Schleiermacher e Hegel, podemos voltar-nos para a crítica diltheiana à metafísica especulativa. Ou seja, é preciso entender especificamente, diz Gadamer, o significado da crítica à fé na razão, à concepção especulativa da história do mundo, à sua dedução apriorística de todos os conceitos. ${ }^{19}$ Contudo é preciso entender, também, o motivo pelo qual Dilthey utiliza termos tão hegelianos para definir a realidade da vida e a consciência histórica como fins últimos da ciência do espírito. Assim, Dilthey esclarece:

Hoje temos que partir da realidade da vida (...). Procuramos entender esta realidade e apresentá-la em conceitos adequados. Na medida em que o espírito objetivo for liberado de uma fundamentação unilateral na razão universal geral que expressa a essência do espírito do mundo, libertado também da construção ideal, torna-se possível um novo conceito do mesmo: nele são acolhidos linguagem, costumes, todo tipo de formas de vida e de estilo de vida, do mesmo modo que família, sociedade civil, estado e direito. Finalmente, encontra-se sob este conceito o que em Hegel distinguia o espírito absoluto do objetivo: arte, religião e filosofia. ${ }^{20}$

Por um lado, encontramos nesta passagem uma reformulação do conceito hegeliano; por outro lado, não podemos negar que há aqui ainda uma espécie de espírito absoluto. Mas o que é, para Dilthey, este espírito que marca uma sua diferença relativamente à posição hegeliana? Trata-se da consciência histórica. É ela, e não o espírito absoluto em seu saber especulativo, que assumirá a tarefa (agora tornada um ideal) de levar a cabo o saber de si mesmo do espírito. Para a consciência histórica, arte, religião e filosofia são formas equiparadas de expressão da vida e não mais, como queria Hegel, momentos da razão em seu processo de desenvolvimento. Não obstante Dilthey e Hegel compartilharem ainda a idéia de que há algum tipo de objetivação, a diferença entre eles está no fato de que, enquanto Hegel tematiza o retorno do espírito como momento da cognição do conceito, para Dilthey o conceito filosófico não tem significado cognitivo, mas

19 Ibidem, p. 349.

20 Idem. 
apenas expressivo. Neste sentido, as objetivações da arte representam o verdadeiro triunfo da hermenêutica.

É por meio da consciência histórica, então, que todos os fenômenos do mundo humano-histórico são tomados como objetos. É precisamente nesta tomada que o espírito conhece mais profundamente a si mesmo e transfere os próprios fenômenos humano-históricos à vitalidade espiritual de onde procederam. Neste sentido, diz Gadamer, "as configurações do espírito objetivo são para a consciência histórica, portanto, objetos do autoconhecimento". ${ }^{21}$

Dilthey está certamente recusando o apriorismo hegeliano. Entretanto,, podemos indagar se não seria ainda a sua posição uma espécie de metafísica. Qual seria este tipo de metafísica pressuposta? E ainda, poderia a consciência histórica remeter ao passado que o apriorismo hegeliano negava?

Outra metáfora da natureza pode lançar algumas luzes sobre estas questões. "A flor é a verdadeira madureza. O fruto não é mais do que a caótica casca do que pertence à planta orgânica." 22 Segundo Gadamer, esta frase de Schleiermacher citada por Dilthey tem a função de caracterizar a posição metafísica estética deste último. O que pretende Dilthey é lançar-se sobre os conteúdos históricos passados que o panteísmo hegeliano tomava com sempre presentes. Deste modo, diz ele que "a história dos movimentos espirituais tem sua vantagem de monumentos que são verdadeiros. Podemos nos equivocar com respeito às intenções, mas não com respeito ao conteúdo da própria interioridade que está expresso em obras". ${ }^{23}$ No que diz respeito aos conceitos de reconstrução e integração estipulados por Gadamer, a teoria diltheiana pretende ter superado tanto Hegel quanto Schleiermacher. Contra o primeiro, afirma a necessidade de manter a consciência da própria finitude. E, em certo sentido, também contra o segundo, afirma que se trata de encontrar a possibilidade de reconstrução e integração na vida. Deste modo, afirma que vida compreende a vida.

É preciso indagar, na perspectiva de Gadamer, se não haveria uma contradição nesta proposta de Dilthey. Ou: de que modo a vida, marcada pela consciência da própria finitude, pode elevar-se à consciência histórica? Gadamer esclarece ainda que a idéia de consciência histórica vem suprir a pretensão da consciência filosófica em conter em si a verdade inteira da história do espírito. Pois, diz ele, "a consciência humana não é um intelecto infinito para o qual tudo seja simultaneamente e presente por igual". ${ }^{24}$

21 Idem, p. 350

22 Leben Schleiermacher, $1^{\text {a }}$ edição, 1870, in: Gadamer, H. G., Verdade e método, p. 352.

23 Leben Schleiermacher, ed. Mulert, 1922, p. XXXI, in: Gadamer, H. G., Verdade e método, p. 352.

24 Gadamer, H. G., Verdade e método, p. 358. 
Mas surge ai um paradoxo. Como entender a identidade absoluta entre consciência e objeto de modo que, por princípio, ela não seja inacessível à consciência histórica finita? Ou como indaga Gadamer: "em que se apóia a sua distinção de elevar-se, apesar disso, sobre si mesma e tornar-se assim capaz de um conhecimento histórico objetivo?"25

Sobre este ponto há uma sutil divergência entre os comentadores da obra de Dilthey. Aqueles que se prendem aos primeiros trabalhos de Dilthey tendem a considerá-lo ainda vinculado a uma epistemologia de cunho psicologista. ${ }^{26}$ No entanto, a tradição filosófica que segue a linha hermenêutico-fenomenológica trata de acompanhar o seu desenvolvimento intelectual enfocando a reestruturação hermenêutica de Dilthey desde a discussão com Husserl. É, portanto, a partir desta disputa intelectual que Dilthey estabelece, como dado originário, o conceito de nexo da vida como um saber.

O ponto de partida de Dilthey é, portanto, a vida, uma vez que esta se encontra apontada para a reflexão. Mas não é só isso. O que deve ficar claro é o fato de que a vida mesma contém saber (que não resultará, explica Gadamer, numa experiência, mas já é sempre uma compreensão). Se tomamos a vida como o ponto de saber reflexivo, devemos admitir que há, aqui, a interiorização (Innesein) que caracteriza a vivência. Vale dizer, há uma espécie de retorno da vida sobre si mesma. É esta reflexividade imanente da vida que determina, também, como o significado surge no nexo vital.

Partindo desta estrutura básica, Dilthey apresenta uma distribuição hierárquica das formas de expressão, pois toma-as como momentos de objetivação dos saberes que estão acima da própria subjetividade. Deste modo, os saberes populares (mais próximos de uma visão natural da vida sobre si mesma) e as grandes obras de arte compartilham a objetividade para além do seu criador. Mas, acima deles e num grau de objetividade cada vez maior, estão as formas de expressão que dominam a vida humana (linguagem, costumes, formas jurídicas, etc.), visto que são sempre conformações do espírito objetivo. Neste sentido, é a dedicação a objetivos comunitários que "liberta o homem da particularidade e do efêmero". ${ }^{27}$

De fato, Dilthey pôs sobre o mesmo fundamento do saber reflexivo imediato da vida ambas as ciências (da natureza e do espírito) e, em conseqüência, impõe às ciências do espírito a metodologia das ciências da natureza. Este é o resultado da influência kantiana assumida por Dilthey, uma vez que ele pretende ter substituído o sujeito lógico pelo sujeito vivente e,

\footnotetext{
25 Idem.

26 José Aguirre, Jean Grondin, entre outros.

27 Gadamer, H. G., Verdade e método, p. 360
} 
com isto, supõe poder reconhecer a regularidade do mundo espiritual acima da causalidade subjetiva.

Finalmente, convém apresentar a consideração de Gadamer acerca do limite da teoria diltheiana. Para ele, o ponto fraco de Dilthey está em seu comprometimento com o modelo cartesiano. Pois ele não distingue entre a dúvida metódica e as dúvidas que aparecem por si mesmas. Desta maneira, a sua teoria põe no mesmo patamar a certeza das ciências e a certeza da vida. Esta identificação não dá à noção de compreensão o sentido de experiência (da vida). Dilthey segue o modelo da hermenêutica romântica, e toma o mundo espiritual como um texto a ser decifrado e compreendido em seu sentido. É por isso, diz Gadamer, que "todo encontro com um texto é, para ele, um auto-encontro do espírito". ${ }^{28}$ Deste modo, Gadamer tem razão em afirmar que, embora Dilthey tenha relevado a significação da experiência da vida, ele foi um pensador do seu tempo. Assim, o fato de não poder considerar a experiência da vida (a partir da própria dúvida que caracteriza a finitude humana) fez com que "sua investigação sobre o passado histórico acabasse sendo um deciframento e não uma experiência histórica". ${ }^{29}$

BRITO, E. O. Historical conscientious and Hermeneutic. Trans/Form/Ação, (São Paulo), v.28(2), 2005, p.149-160.

- ABSTRACT: The aim of this paper is to present the steps of Gadamer's reform of Dilthey's hermeneutic (developed under the modern concept of life experience, which was taken to be the grounding/basis of historical self-conscience) and to expose the new concepts of reason and human existence within Gadamer's theory, when he introduced the concept of finitude to the concept of human life experience.

- KEYWORDS: Hermeneutic, historical conscientious, True and finitude.

\section{Referências bibliográficas}

AGUIRRE, J. M., Raison critique et raison herméneutique, $1^{\mathrm{a}}$ ed, Paris: Les Editions du Cerf, 1998.

. "Pensar com Gadamer e Habermas", in: Revista Portuguesa de Filosofia, tomo LVI, julho/dez., Faculdade de Filosofia de Braga, 2000.

DILTHEY. W., El mundo histórico, $1^{\text {a }}$ Ed., tr. Eugenio Imaz. : México: Fondo de Cultura Econômica, 1944.

28 Idem.

29 Idem, p. 367. 
DILTHEY. W., Psicologia y teoria Del conhecimento, $1^{\text {a }}$ Ed., tr. Eugenio Imaz. México: Fondo de Cultura Econômica, 1945.

GADAMER H. G., Verdade e método, $4^{a}$ ed., tr. Flávio P. Meurer. Petrópolis: Vozes, 2002.

GRONDIN. J., Introducción a la hermenéutica filosófica, $1^{\text {a }}$ ed., Barcelona: Editorial Herder, 1999

HEGEL, G. W., F. Lecciones sobre la Filosofía de la Historia Universal, tr. José Gaos. $4^{\mathrm{a}}$ Ed., Madrid: Revista de Occidente: , 1964

HYPPOLYTE, J. Genèse et estructure de la Phénoménologie de l'esprit de Hegel, Paris: Aubier, 1978.

SCHLEIERMACHER, F. D. E., Hermenêutica - arte e técnica da interpretação, tr. Celso R. Braida, Petrópolis: Vozes, 1999. 